ECCOMAS

Proceedia
COMPDYN 2021

$8^{\text {th }}$ ECCOMAS Thematic Conference on Computational Methods in Structural Dynamics and Earthquake Engineering M. Papadrakakis, M. Fragiadakis (eds.)

\title{
EXPERIMENTAL INVESTIGATION OF SHEAR STRENGTH OF SOLID BRICK URM WALLS RETROFITTED WITH TRM JACKET
}

\author{
Athanasia K. Thomoglou ${ }^{1}$, Athanasios K. Karabinis ${ }^{2}$ \\ ${ }^{1}$ Civil Engineering Department, Democritus University of Thrace (DUTh), \\ Kimmeria, 67100 Xanthi, Greece \\ e-mail: athomogl@civil.duth.gr \\ ${ }^{2}$ Civil Engineering Department, Democritus University of Thrace (DUTh), \\ Kimmeria, 67100 Xanthi, Greece \\ e-mail:karabin@civil.duth.gr
}

\begin{abstract}
This study is part of an experimental program on full-scale strengthened Un-Reinforced Masonry (URM) walls with Textile reinforced mortars (TRM). Four solid brick walls (one control and three strengthened specimens with central opening), were tested under the diagonal tension (shear) test method in order to investigate the effectiveness of the strengthening system on the in-plane behavior of the walls. All the URM panels consist of solid bricks and a high strength binder mortar. Both of them have increased mechanical properties leading to improved shear behavior of the masonry walls. Several parameters pertaining to the in-plane shear behavior of the retrofitted panels were investigated, including shear capacity, failure modes, the number of layers of the external TRM jacket and the existence of the central opening of the wall. The experimental work allowed an evaluation of the shear behavior in the case of the bidirectional textile (TRM) system applied on URM walls. The experimental results of URM and retrofitted walls with different layers are compared with each other. The purpose is to investigate in depth and to draw conclusions about the in-plane shear behavior.
\end{abstract}

Keywords: TRM, solid brick URM, in-plane performance, seismic strengthening, diagonal compression test, wall's opening. 


\section{INTRODUCTION}

The existence of the doors and/or windows openings of the Unreinforced masonry (URM) walls significantly affects the shear behavior of the structure. Hence, there is an urgent need to investigate the influence of the retrofitting technique on URM walls with openings. In the field of rehabilitation and strengthening of the existing masonry buildings, Textile Reinforced Mortar (TRM) has attracted considerable research interest as an alternative to the traditional strengthening methods due to its better compatibility with the URM substrate, fire resistance, excellent mechanical strength and stiffness in the direction of the fibers, while it improves the seismic capacity of URM walls (Thomoglou et al 2020). Nevertheless, there is limited experimental research on full-scale walls.

The existence of openings in masonry walls is often responsible for in-plane collapse mechanism creation, leading to the entire building collapse (Chalioris et al. 2013, Chalioris et al. 2015). Considering this critical parameter, there is a limited experimental study on retrofitting masonry walls with openings. Several works on infill masonry walls with openings were carried out by Kakaletsis and Karayannis (2008), Kakaletsis and Karayannis (2009), Decanini et al. (2014), Mansouri et al. (2014), Sigmund and Penava (2014), Tasnimi and Mohebkhah (2011), or without openings by Lee et al. (2010), Rousakis (2017) and Rousakis (2020). From the abovementioned research, it is concluded that openings have a significant effect on the characteristics of masonry infill walls, such as failure mode and lateral strength, and ductility reducing shear strength, stiffness, and energy dissipation capacity.

The work concerns diagonal compression tests on solid brick URM and retrofitted walls with TRM jacket on both sides of the walls. The TRM reinforcement system comprises one, two, or three plies of glass fiber mesh in a cement mortar matrix. This strengthening method has an advantage over other traditional solutions in easy application, excellent adhesion of the mortar to the brick substrate, high tensile strength, and low elasticity increasing compatibility with masonry. The purpose is to investigate and to draw conclusions about the shear behavior of strengthened full-scale brick URM walls with a central opening.

\section{EXPERIMENTAL PROGRAMM}

This experimental study deals with full-scale URM walls comprising solid bricks and a high strength binder mortar (Durostick D-31). The TRM strengthening system consist of one, two or three layers of glass mesh in a cementitious matrix applied to both of the specimen with central opening. The strengthening concept is based on the observation that the strengthening mortar matrix plays a key role to the contribution of the total shear capacity (Thomoglou et al. 2020). All the experiments were conducted at the Laboratory of Reinforced Concrete and Seismic Design of Structures of the Department of Civil Engineering of the Democritus University of Thrace.

\section{MECHANICAL PROPERTIES OF MATERIALS}

\subsection{Mechanical properties of bricks and mortar and exterior strengthening}

The nominal dimensions of the solid bricks were $200 \mathrm{~mm}$ (Length) x $100 \mathrm{~mm}$ (Width) x 50 mm (Height) (Figure 1a). The compressive behavior of brick units is determined in two load directions: perpendicular and parallel to the bed joints. Six units were tested in total under an axial load after grinding of their loading surfaces according to procedures established in the European standard EN 772-1 (2000). Two displacement transducers (LVDTs) and a laser meter were used to measure the vertical and horizontal deformations, $\Delta \mathrm{v}$ and $\Delta \mathrm{h}$ (Thomoglou et al. 2018). The compressive strength of the bricks equals to $116.17 \mathrm{MPa}$. A render mortar of 
$20 \mathrm{M}$ class was used to construct all the walls, with a nominal mortar thickness of about 10 $\mathrm{mm}$. The 28-day compressive strength of the Durostick D-31 mortar obtained by testing 40 $\mathrm{mm} \times 40 \mathrm{~mm} \times 160 \mathrm{~mm}$ mortar prisms according to EN 1015-11 (1993) with an average value of $38.15 \mathrm{MPa}$, while the tensile strength is $15.76 \mathrm{MPa}$ (Figure 1b).

Prior to the application of the TRM jacket, the masonry specimen was coated with lightheavy, reinforced cementitious mortar (SikaRep ${ }^{\circledR}-200$ Multi) in order to smooth the protrusions and to get a flat layer on the external surface. The exterior strengthening system consisted of 1, 2 or 3 plies of glass grid embedded into a cementitious matrix. The glass fibers were arranged along two rectangular directions with axial spacing of $18.1 \mathrm{~mm}$ in the longitudinal and $14.2 \mathrm{~mm}$ in the lateral direction, respectively, as shown in Figure 1c, while its mass was $360 \mathrm{~g} / \mathrm{m}^{2}$ per unit area. The modulus of elasticity in the longitudinal direction was $80 \mathrm{GPa}$. Fiber reinforced cementitious mortar with pozzolanic admixtures had a 28-day compressive and flexural strength of $28.85 \mathrm{MPa}$ (based on EN 1015-11) and 6.78MPa, respectively, while the Modulus of elasticity was $8.03 \mathrm{GPa}$ (according to the manufacturer) (Thomoglou et al. 2019b).

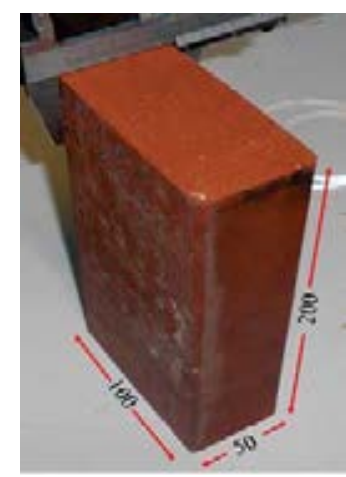

a)

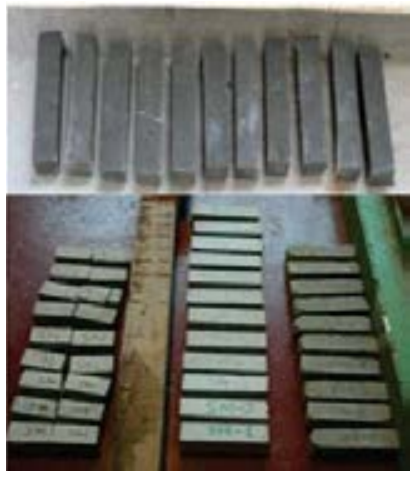

b)

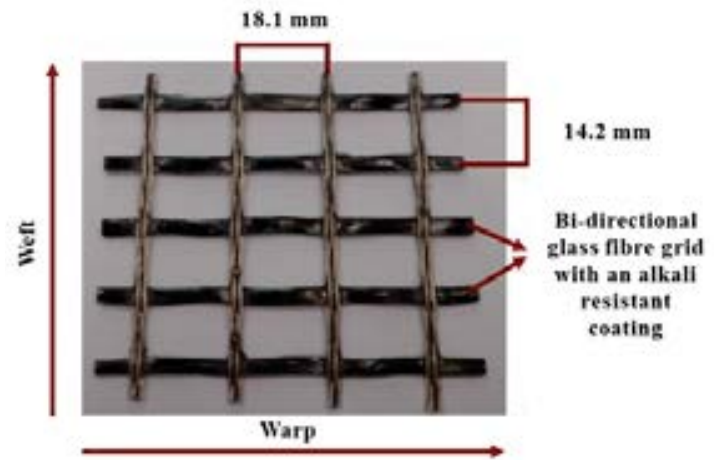

c)

Figure 1 a) Dimensions of solid brick, b) Maturing mortar prisms and test pieces after a three-point bending test, c) Dimensions of fiberglass grid SikaWrap ${ }^{\circledR}-350$ GGrid.

\section{TEST SET-UP AND LOADING}

\subsection{Main headings}

In order to investigate the shear behavior of the strengthened walls under lateral loading, the diagonal compression test, was standardized by ASTM E 519-07 (ASTM 2010) to determine the shear capacity of $1200 \mathrm{~mm}$ x $1200 \mathrm{~mm}$ masonry panels. The specimens were loaded in compression along one diagonal to cause tension failure, with the specimens splitting apart parallel to the direction of loading. For this study, four specimens were constructed in full scale and the thickness for all panels was $210 \mathrm{~mm}$. All specimens were with central opening (one control and three strengthened walls with 1-ply, 2-ply or, 3-ply glass TRM, respectively). The dimensions of the opening are $450 \mathrm{~mm}$ (length) and $300 \mathrm{~mm}$ (height) (see Figure 2a). The layers of the glass TRM were applied over each side of the panel.

The in-plane test setup comprises of two steel loading shoes, according to ASTM E519, placed diagonally opposite to the corners of the specimen, while they attached the upper shoe to the MTS servo-hydraulic piston (Figure 2b). Diagonal compression was applied via a 450 kN MTS servo-hydraulic piston. High-performance shrinkage compensated a cementitious, 
free-flowing mortar SikaGrout-312 HP which was used to fill the two shoes (capping), maturing for at least 24 hours.

The compressive load applied uniaxially and monotonically to the failure point at a rate of $0.01 \mathrm{~mm} / \mathrm{s}$. The diagonal compression test was widely used to broaden the knowledge on masonry subjected to in-plane behavior. Although diagonal compression does not reproduce a field condition behavior of the masonry field, however, it is more conservative because of the limited value of the vertical load and is standardized according to ASTM 2010, (Thomoglou et al. 2019a).

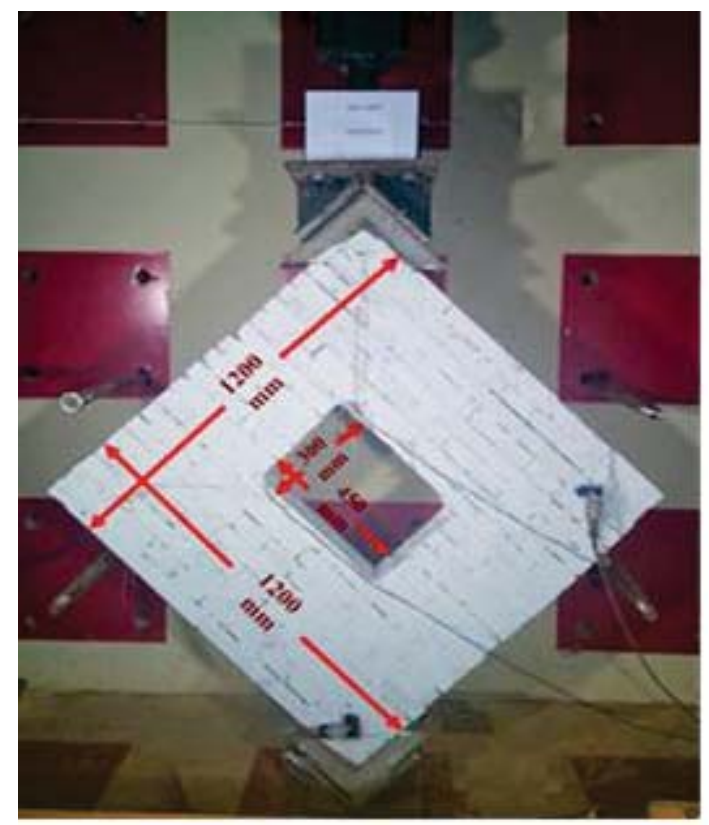

a)

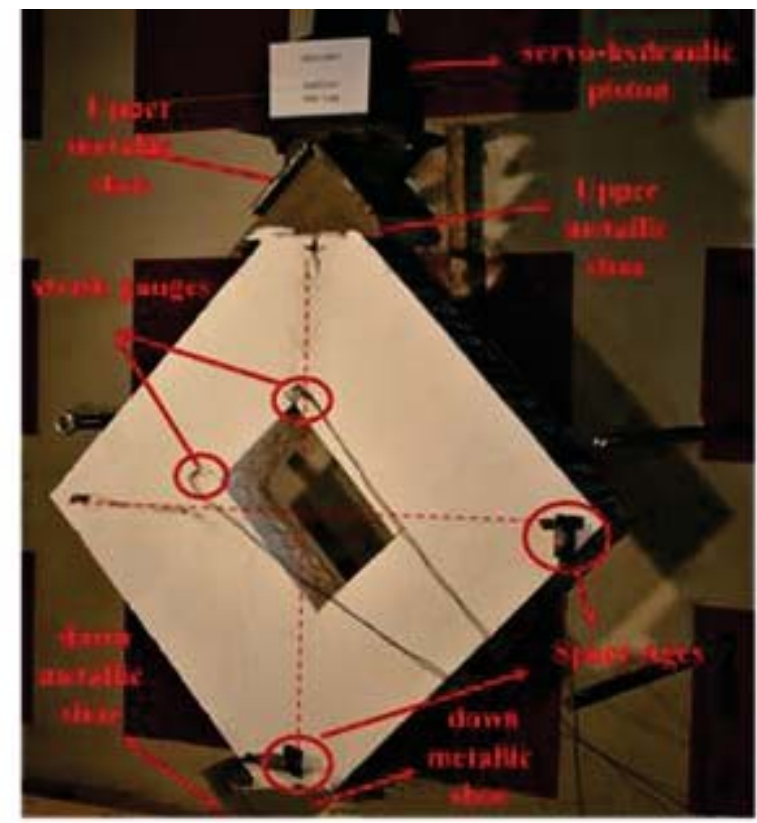

b)

Figure 2 a) Experimental set up of solid brick URM wall with central opening, b) Arrangement of measuring instruments on the URM wall.

\section{RESULTS-DISCUSSION}

\subsection{Displacement Force Diagram}

The mechanical parameters of the tested specimens are presented in Table 1. The results of the experimental tests on the maximum applied load, the ultimate shear stress, the ultimate displacement, the ultimate shear strain, and the failure mode for each specimen are presented in columns (2)-(6) of Table 1, respectively. The production of the reinforcement is defined as the ratio between the maximum load applied to each strengthened panel to the unreinforced control wall. It can be observed that there is an increase in shear capacity and therefore an improvement in the production of external strengthening amounting to $339 \%, 470 \%$, and $701 \%$ for 1, 2, and 3-ply TRM jacket, respectively, compared to the value of $61.49 \mathrm{kN}$ of the control wall. Besides, the displacement of the retrofitted specimen shows 2.31, 2.71 and 3.04 times the value of $4.19 \mathrm{~mm}$ of the control one, for 1, 2, and 3-ply TRM jacket, respectively.

The results from those masonry specimens with a central opening retrofitted with 1 to 3ply TRM jacket are summarized in the response curves of Figure 3 and compared with each other. In the load-displacement diagram, the strengthened masonry specimen with central opening and 3-ply of fiberglass mesh (SS-O-UMG3), presenting more plastic behavior and 
showing the best shear response from all the strengthened walls. An important observation is that as the shear capacity so the ultimate displacement of retrofitted masonry walls increases proportionally to the amount of TRM for 1 and 3 plies.

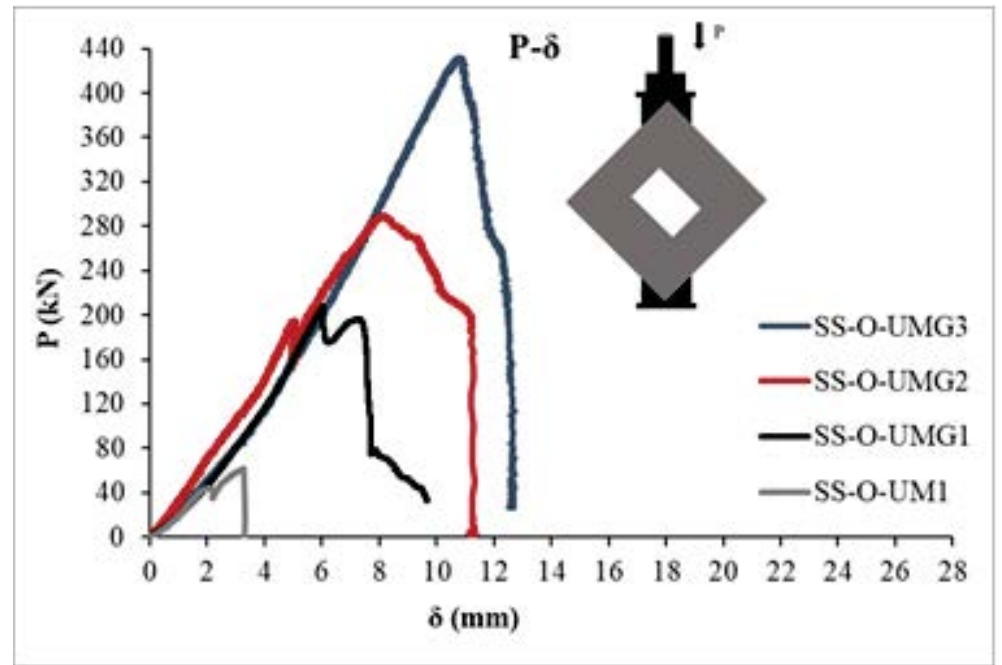

Figure 3 Experimental set up of solid brick URM wall with central opening.

\begin{tabular}{|c|c|c|c|c|c|c|}
\hline $\begin{array}{l}\text { Specimer } \\
\text { Codes }\end{array}$ & $\begin{array}{c}\text { Plies of } \\
\text { TRM } \\
\text { textiles }\end{array}$ & $\begin{array}{c}\text { Maximum } \\
\text { applied } \\
\text { failure } \\
\text { load } \\
\mathrm{P}_{\mathrm{u}} \\
(\mathrm{kN}) \\
(3)\end{array}$ & $\begin{array}{l}\text { Ultimate } \\
\text { Shear } \\
\text { stress } \\
\tau_{\mathrm{u}} \\
(\mathrm{Mpa}) \\
(4)\end{array}$ & $\begin{array}{c}\text { Displace } \\
\text { ment } \\
\delta_{\mathrm{u}} \\
(\mathrm{mm}) \\
(5)\end{array}$ & $\begin{array}{c}\text { Ultimate } \\
\text { Shear } \\
\text { strain } \\
\gamma_{\mathrm{u}} \\
(\mathrm{mm} / \mathrm{mm}) \\
(6)\end{array}$ & Failure Mode \\
\hline $\begin{array}{l}\text { SS-O- } \\
\text { UM1 }\end{array}$ & Control & 61.49 & 0.17 & 4.19 & 0.0028 & SF \\
\hline $\begin{array}{l}\text { SS-O- } \\
\text { UMG1 }\end{array}$ & 1 ply & 208.19 & 0.59 & 9.67 & 0.0051 & $\begin{array}{c}\text { TRM failure- } \\
\text { DT }\end{array}$ \\
\hline $\begin{array}{l}\text { SS-O- } \\
\text { UMG2 }\end{array}$ & 2 plies & 289.23 & 0.82 & 11.35 & 0.0068 & $\begin{array}{c}\text { TRM failure- } \\
\text { DT }\end{array}$ \\
\hline $\begin{array}{l}\text { SS-O- } \\
\text { UMG3 }\end{array}$ & 3 plies & 431.20 & 1.22 & 12.72 & 0.0091 & $\begin{array}{c}\text { TRM failure- } \\
\text { DT }\end{array}$ \\
\hline
\end{tabular}

DT: Diagonal Tension, SF: Shear Friction

Table 1: Experimental results.

\subsection{URM Failure Modes}

The typical crack patterns of the four masonry walls after shear failure are illustrated in Figure 4 . The control wall with central opening showed a brittle failure caused by the loss of the bond between the mortar and the bricks, as well as a diagonal tensile stress with a simultaneous fracture of the mortar and bricks, which caused a stair-step cracking and shear friction (Thomoglou et al. 2019a). Hence, the failure mode of the control wall with central opening (SS-O-UM1) is a shear friction. The failure mode of the strengthened wall with 1-ply (SS-O- 
UMG1) is diagonal tension, which appears with a thorough crack along the entire length of the diagonal parallel to the direction of the load and across the width of the panel. The evolution of the diagonal crack started from the point where the maximum concentrated tensile stresses appear. This point is the two opposite corners of the hole in the vertical direction, while at the two opposite corners of the other direction maximum compressive stresses develop. Also, two cracks are developed from the external side of the panel and end at the two opposite corners of the opening, which are located almost perpendicular to the load direction (Figure 4a)-b).

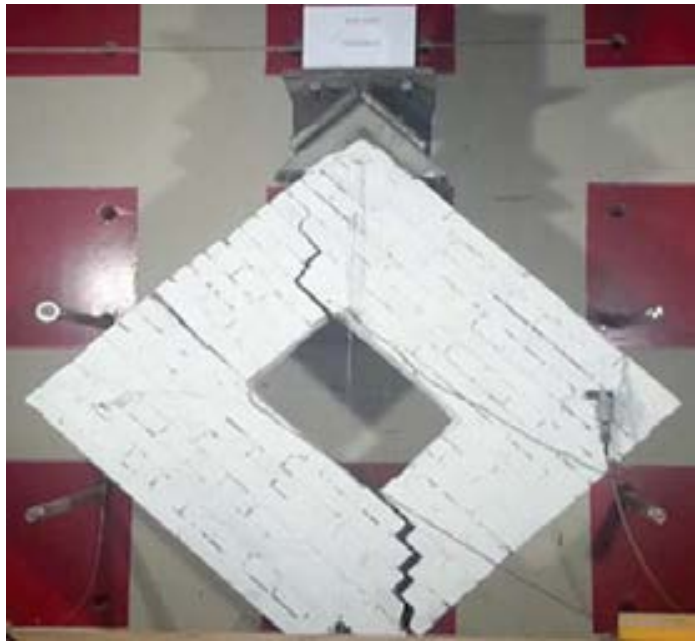

a)

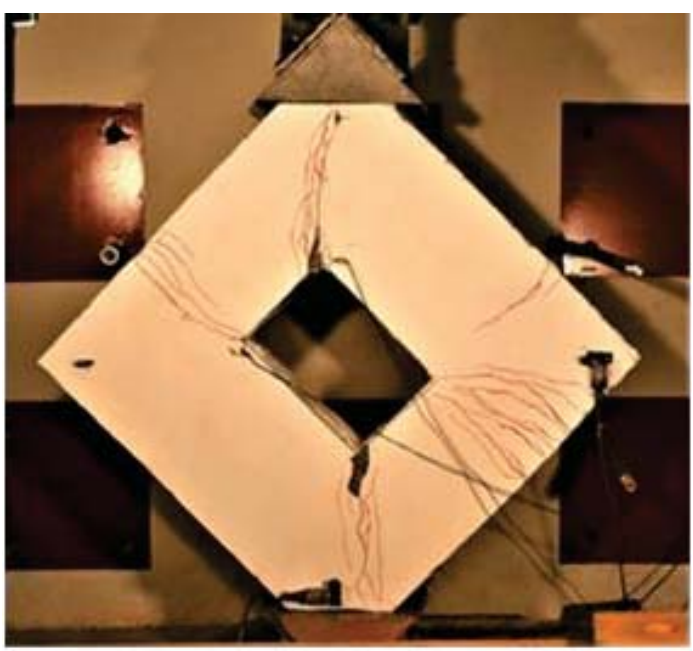

c)

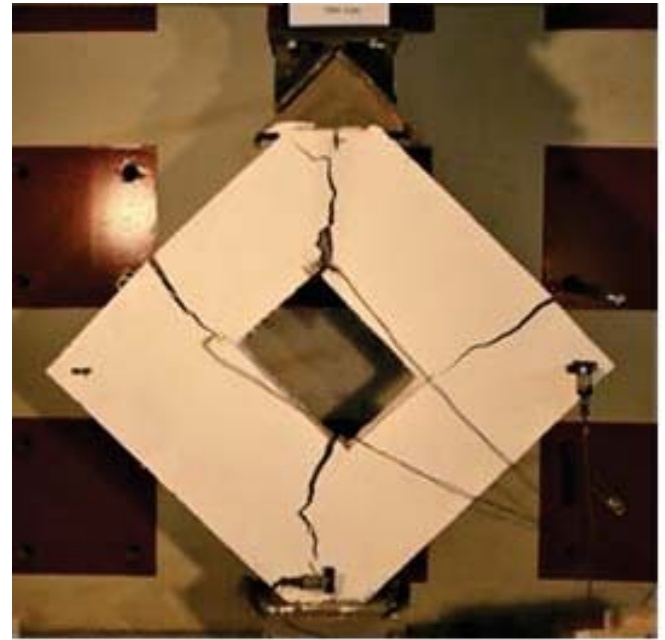

b)

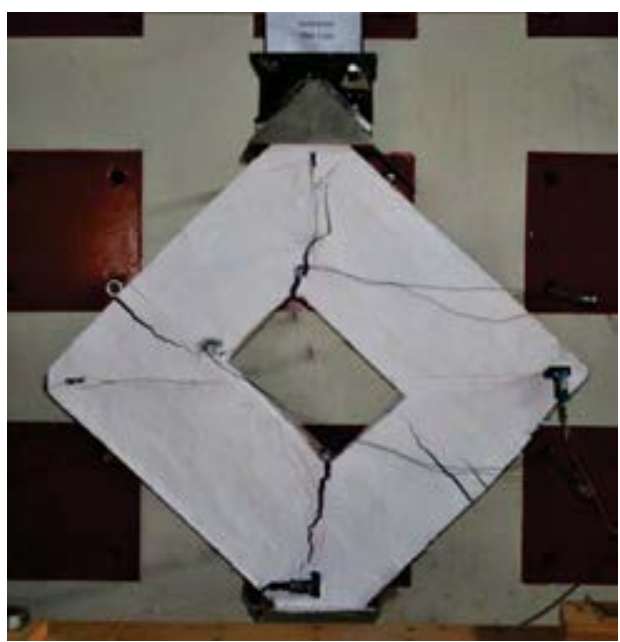

d)

Figure 4 Failure mode of a) control brick URM wall (SS-O-UM1), b), c), d) strengthened wall with 1-ply (SS-OUMG1), 2-ply (SS-O-UMG2) and 3-ply (SS-O-UMG3) glass textile, respectively.

The failure mode of the retrofitted solid brick URM (SS-O-UMG3) with 3 plies of glass textile and a central opening is similar to the specimens with 1 and 2 plies of TRM jacket (see Table 1 and Figure 4 b)-d)). Nevertheless, a wider vertical crack is observed and parts of the strengthening mortar of the TRM jacket are effectively detached. The glass textile failure is observed here as well as in the case with 1 and 2 plies (SS-O-UMG2, SS-O-UMG3), respectively (Figure 4b)-d)). Finally, the effectiveness of this significant strengthening technical is highlighted, if we include the fact of preventing the final collapse of the masonry, which is very important for the safety of human and material resources. 


\section{AKNOWLEGMENTS}

We acknowledge KEVE. SA for the supply of Orthoblock K300 bricks and building masonry specimens, as well as Sika Hellas SA for providing all masonry strengthened materials and for our excellent cooperation.

\section{CONCLUSIONS}

A full-scale experimental investigation was aimed to assess the effectiveness of the TRM external jacket in order to improve the in-plane behavior of the four solid brick specimens with a central opening. The masonry panels were retrofitted using three different configurations (with 1, 2, 3 plies of a both-sided TRM application) and were tested under monotonic diagonal tension (shear) test. From the aforementioned results, the following concluding observations arise:

- The TRM jacket has improved the shear capacity and deformation capacity, which caused the failure of the strengthened walls in a more plastic way.

- There is an increase in shear capacity and therefore an improvement in the production of external strengthening amounting to $339 \%, 470 \%$, and $701 \%$ for 1,2 , and 3 -ply TRM jacket, respectively, compared to the value of $61.49 \mathrm{kN}$ of the control wall.

- The displacement of the retrofitted specimens shows 2.31, 2.71 and 3.04 times for 1,2, and 3-ply TRM jacket, respectively, compared to the value of $4.19 \mathrm{~mm}$ of the control wall.

- The best shear behavior was demonstrated by the masonry specimen with 3-ply of TRM and a central opening of solid bricks compared to all masonry walls.

- The failure mode of the control wall with central opening is shear friction, while the strengthened masonry specimens exhibited TRM failure and diagonal tension.

- The tests results demonstrated that the glass TRM jacket plays an important role in retaining and protecting the solid brick masonry wall. The strengthening system prevents the abrupt reduction of the resistance and significantly reduces the brittle behavior, avoiding an explosive collapse.

\section{REFERENCES}

[1] ASTM. "Standard test methods for diagonal tension (shear) in masonry assemblages. ASTM E519 / E519M”, West Conshohocken, PA., DOI: 10.1520/E0519_E0519M-10, 2010.

[2] Chalioris, C. E., Favvata, M. J., Alexandri, V. G., \& Karayannis, C. G., Rehabilitation of a partially collapsed masonry traditional tobacco warehouse of the late 19th century. In COMPDYN 2013: proceedings of the 4th international conference on computational methods in structural dynamics and earthquake engineering, Kos Island, Greece, paper (No. 1596, pp. 12-14), 2013.

[3] Chalioris C.E., Tsioukas V.E., Karayannis C.G., Recording and Rehabilitation Procedures for Historic Masonry Buildings, Computational Methods in Applied Sciences, Vol. 
37, chapter in the book: "Seismic Assessment, Behavior and Retrofit of Heritage Buildings and Monuments", Psycharis et al. (eds.), pp. 341-364, 2015.

[4] Decanini LD, Liberatore L, Mollaioli F., Strength and stiffness reduction factors for infilled frames with openings. Earthq Eng Eng, Vib 2014; 13(3): 437-54, 2014.

[5] Kakaletsis D. and Karayannis C., Influence of masonry strength and openings on infilled R/C frames under cycling loading. Journal of Earthquake Engineering 12(2): 197-221, 2008.

[6] Lee, Y.-H., Kim, M.-S., Byon, E.-H., \& Kim, H.-C., Experimental Investigation of The Shear Strengthening of Unreinforced Masonry Infilled RC Frames Using CFRP Sheet. Journal of the Earthquake Engineering Society of Korea, 14(1), 63-70. https://doi.org/10.5000/eesk.2010.14.1.063, 2010.

[7] Mansouri A, Marefat MS and Khanmohammadi M, Experimental evaluation of seismic performance of low shear strength masonry infills with openings in reinforced concrete frames with deficient seismic details. Structural Design of Tall and Special Buildings 23(15): 1190-1210, 2014.

[8] Rousakis, T.C., Rouka, D., Kaloudaki, A., Kwiecien A., Gams, M.,Viskovic, A., Zajac, B. Fast Retrofitting of Strong Wall Infill of RC buildings with Fiber Sheets Impregnated with Highly Deformable Polymer. 25th International Conference on Composites/Nano Engineering (ICCE-25), Rome, Italy, 16-22 July, 2017.

[9] Rousakis T, Ilki A, Kwiecien A, Viskovic A, Gams M, Triller P, Ghiassi B, Benedetti A, Rakicevic Z, Colla C, Halici OF, Zając B, Hojdys Ł, Krajewski P, Rizzo F, Vanian V, Sapalidis A, Papadouli E, Bogdanovic A., Deformable polyurethane joints and fibre grids for resilient seismic performance of reinforced concrete frames with orthoblock brick infills, Polymers, 12(12), https://doi.org/10.3390/polym12122869, 2020.

[10] Sigmund V and Penava D, Influence of openings, with and without confinement, on cyclic response of infilled RC frames - an experimental study. Journal of Earthquake Engineering 18(1): 113-146, 2014.

[11] Tasnimi AA and Mohebkhah A, Investigation on the behavior of brick-infilled steel frames with openings, experimental and analytical approaches, Engineering Structures 33(3): 968-980, 2011.

[12] Thomoglou A., Rousakis T. and Karabinis A., Experimental Investigation and 3d Finite Element Analysis of solid and hollow clay bricks, ICCE-26th Annual International Conference on Composites/Nano Engineering, Paris, France, 2018.

[13] Thomoglou A., Rousakis T. and Karabinis A., Investigation of failure modes of URM walls strengthened with TRM subjected to in plane seismic loads, 2nd International Conference on Natural Hazards \& Infrastructure, Greece, 2019a.

[14] Thomoglou A., Rousakis T. and Karabinis A., Experimental Investigation of Shear Behavior of URM strengthened with TRM, 4nd Hellenic Conference Mechanical Seismology, 5-7 September, Athens, Greece, 2019b.

[15] Thomoglou A., Rousakis T., Achillopoulou D. and Karabinis A., Ultimate Shear Strength Prediction Model for Unreinforced Masonry Retrofitted Externally with Textile Reinforced Mortar, Earthquakes and Structures, 19 (6) 000-000, DOI: https://doi.org/10.12989/eas.2020.19.6.000, 2020. 